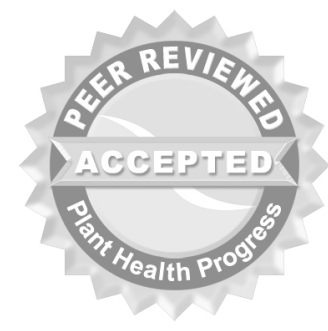

(C) 2013 Plant Management Network.

Accepted for publication 17 December 2012. Published 22 January 2013.

\title{
Identification of Tobacco streak virus Associated With a Virus-like Mottle Symptom on Hosta
}

John R. Fisher, Ohio Department of Agriculture, Plant Health Diagnostic Laboratory, Plant Health Division, Reynoldsburg, OH 43068

Corresponding author: John R. Fisher. jfisher@agri.ohio.gov

Fisher, J. R. 2013. Identification of Tobacco streak virus associated with a virus-like mottle symptom on Hosta. Online. Plant Health Progress doi:10.1094/PHP-2013-122-01-BR.

Tobacco streak virus (TSV) is the type species of the Ilarvirus genus of the family Bromoviridae (4), and is transmitted mechanically through thrips feeding, by pollen (5), and by seed (3). The virus has a tripartite genome of single-stranded messenger-sense RNA which encodes four non-structural proteins and a single structural capsid protein (4). The movement protein and capsid protein encoding genes are located on the 5' half and 3' half, respectively, of RNA 3 (4).

In the spring of 2010, a Hosta sp. 'Fried Green Tomatoes' plant displaying a virus-like mottle symptom (Fig. 1) was submitted to the Ohio Plant Diagnostic Network for analysis. Hosta sp. 'Fried Green Tomatoes' is a solid green sport of the variegated Hosta sp. 'Guacamole' (7), and the submitted sample was collected from a nursery block of approximately 100 plants grown from bare root plugs imported from Europe, a majority of which showed the symptom. The sample tested positive for TSV and negative for the Potyvirus group, Alfalfa mosaic, Arabis mosaic, Cucumber mosaic, Hosta virus X, Impatiens necrotic spot, Lily symptomless, Tobacco mosaic, Tobacco ringspot, Tomato mosaic, Tomato ringspot, and Tomato spotted wilt viruses by enzyme-linked immunosorbent assays (ELISA) using commercially available antibodies (Agdia Inc., Elkhart, IN). The sample also tested negative for Tobacco rattle virus by RT-PCR.

Double-stranded ribonucleic acid (dsRNA) was purified from symptomatic tissue as previously described (6) with no visible dsRNAs detected using agarose gel electrophoresis. However, cDNAs were synthesized from purified dsRNA template as previously described (1). For immunocapture reverse transcription (IC-RT), magnetic beads conjugated with sheep anti-rabbit IgG were incubated with polyclonal rabbit anti-TSV IgG (Agdia, Inc.) (2). Leaf tissue samples were extracted, incubated with TSV-conjugated beads, washed, and cDNAs synthesized from bound virions (2). Three full length TSV RNA 3 sequences (accession no. FJ655173.1, FJ403377.1, Xoo435.1), one movement protein (MP) sequence (accession no. DQ141601.1), and five coat protein (CP) sequences (accession no. AY606066.1, DQ864458.1, EU375481.1, GQ370526.1, HM622157.1) were aligned and used to design two sets of TSV-specific primers to amplify the MP (TSV fwd69: 5'-CCTACAAGTY GAGACCATTGGTC-3'; TSV rev1111: 5'CCATGTCTTACWCAACCSAACARTC-3') and CP (TSV fwd1190: 5GCTTCTCGGACTTACCTGRGATG-3'; TSV rev2160: 5'-

GGTTTYCCAYGGAAATCGTCCGATTC-3'; Integrated DNA Technologies Inc., Coralville, IA) open reading frames (ORFs). Five $\mu \mathrm{L}$ of $\mathrm{cDNA}$ or sterile water was used as template for separate PCR reactions. Amplification was done in $25 \mu \mathrm{L}$ reactions $\left(1.5 \mathrm{mM} \mathrm{MgCl}_{2}, 0.2 \mathrm{mM}\right.$ dNTP mix, $0.2 \mu \mathrm{M}$ primer pair, 0.625 units GoTaq Flexi polymerase (Promega Inc., Madison, WI) with the cycling parameters of $94^{\circ} \mathrm{C}(2 \mathrm{~min}), 40$ cycles of $94^{\circ} \mathrm{C}(45 \mathrm{sec}), 55^{\circ} \mathrm{C}(30 \mathrm{sec}), 72^{\circ} \mathrm{C}(6 \mathrm{O}$ sec), and final extension of $72^{\circ} \mathrm{C}(10 \mathrm{~min})$. 


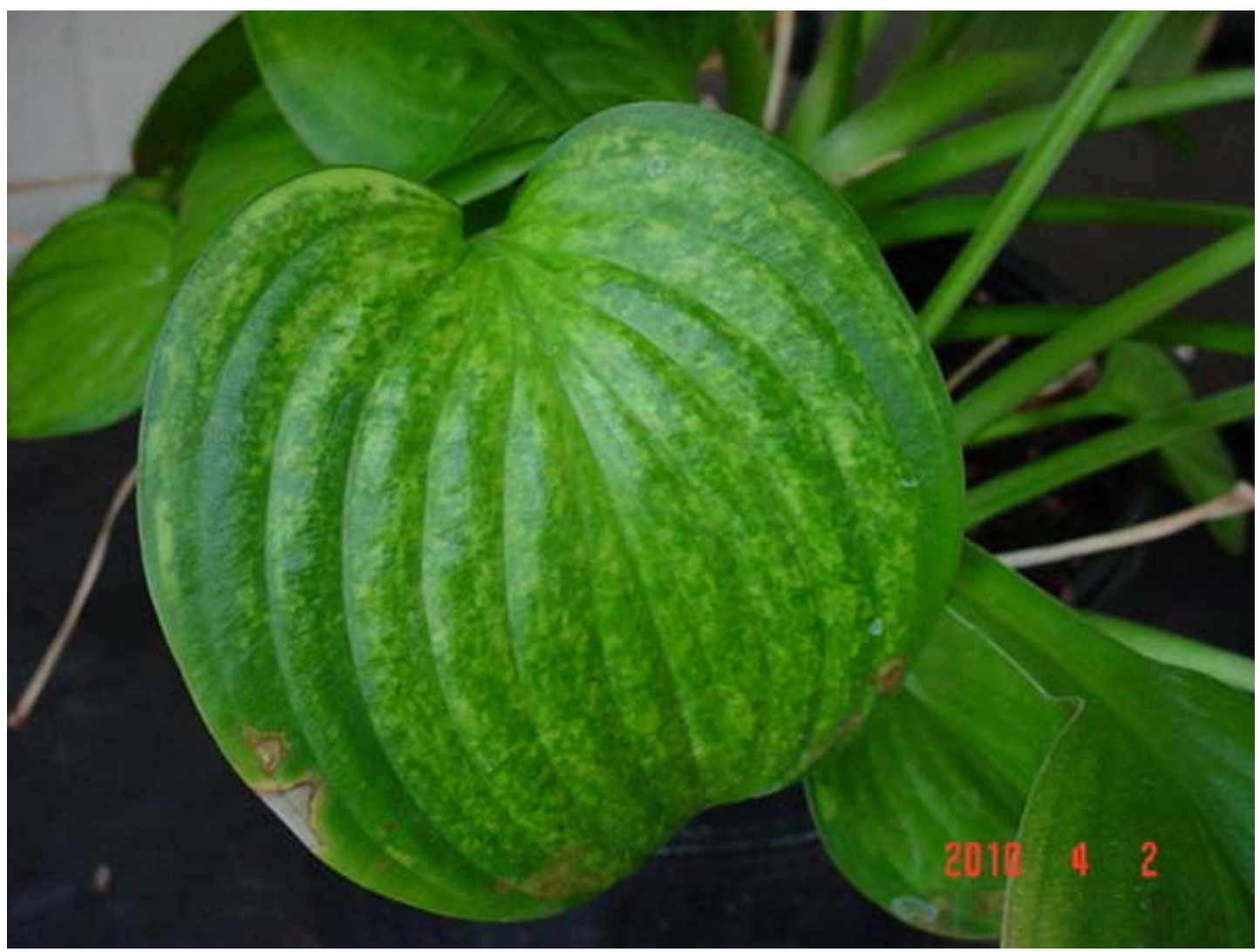

A

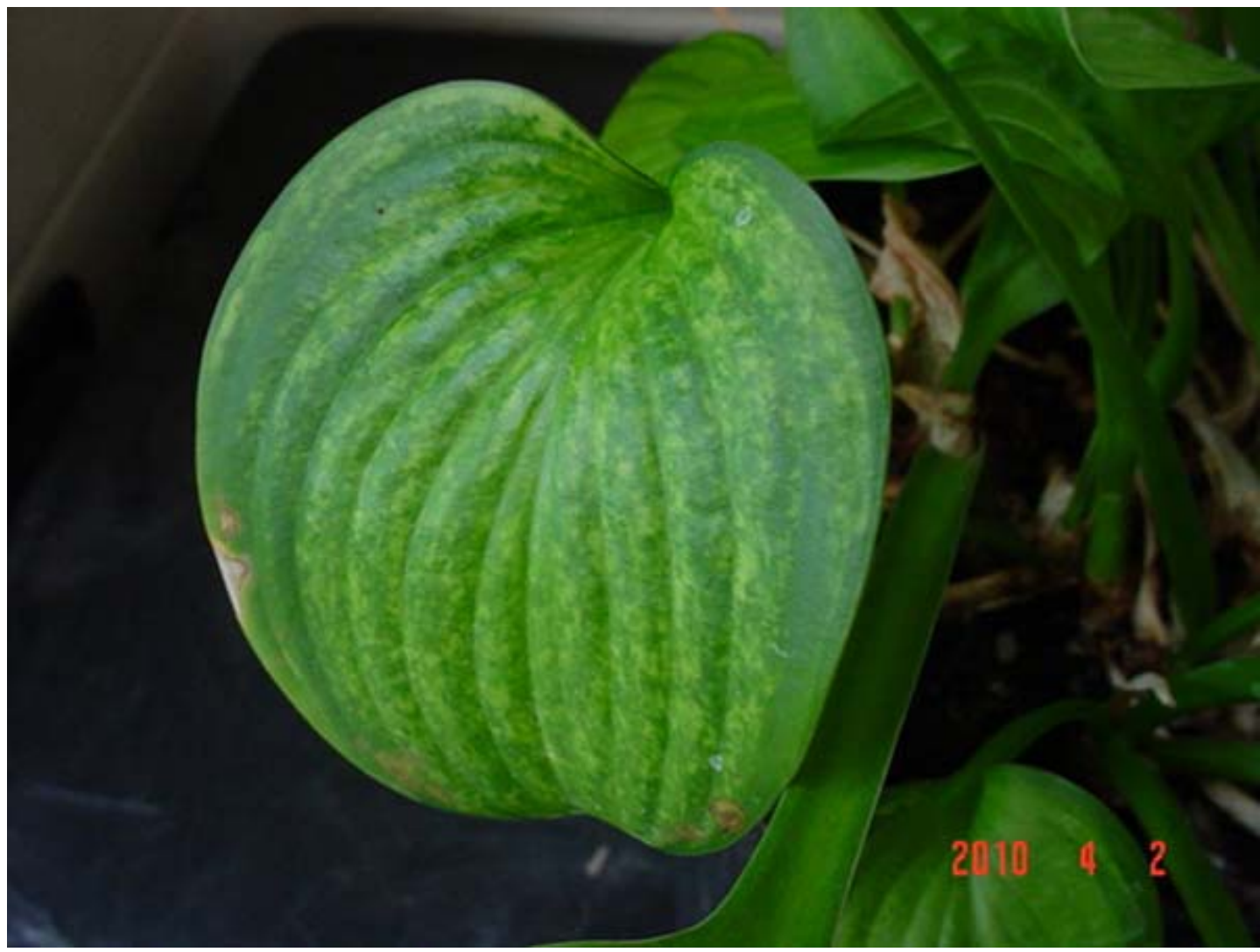

B

Fig. 1. Virus-like mottle symptom observed on Hosta sp. 'Fried Green Tomatoes.' 
cDNAs synthesized from immunocaptured virions and dsRNA template amplified clear products with the MP and CP primers (Fig. 2). The amplicons were excised, purified from the agarose, and cloned into pGEM-T vector as previously described $(1,2)$. Colonies were screened for inserts which were subsequently sequenced. Sequences were assembled and subjected to pairwise and multiple sequence alignments $(1,2)$. Finally, ORFs were translated using Genedoc (Genedoc vers. 2.6.001, 2000, NRBSC, Pittsburgh, PA). Ten MP and ten $\mathrm{CP}$ amplicon clones, five each from cDNAs from immunocaptured virions and dsRNA template, were sequenced and the sequences deposited in GenBank (accession nos. JX417982-JX418001). Eight of ten MP clones were 1040 nucleotides (nt) (two were truncated by one and seven bases on their 5' ends, respectively), encompassing the 873 nt MP ORF. MP clones shared 99.4-100\% nt identity with a mean identity of $99.8 \%$. When translated, they had $99.0-100 \%$ predicted amino acid (aa) identity with a mean of $99.8 \%$. The predicted movement protein was 290 aa. Nine of ten CP clones were 950 nt (one had a three base deletion), encompassing the $717 \mathrm{nt}$ CP ORF. CP clones had 98.7-100\% nt identity with a mean of $99.6 \%$ and a translated $98.0-100 \%$ predicted aa identity with a $99.2 \%$ mean. The predicted coat protein was 238 aa. A BLASTn search of the NCBI database resulted in a match with a TSV isolate from Illinois soybean (accession no. FJ403377.1) that was 99\% identical (100\% query coverage) to both the TSV-Hosta MP and CP genes.

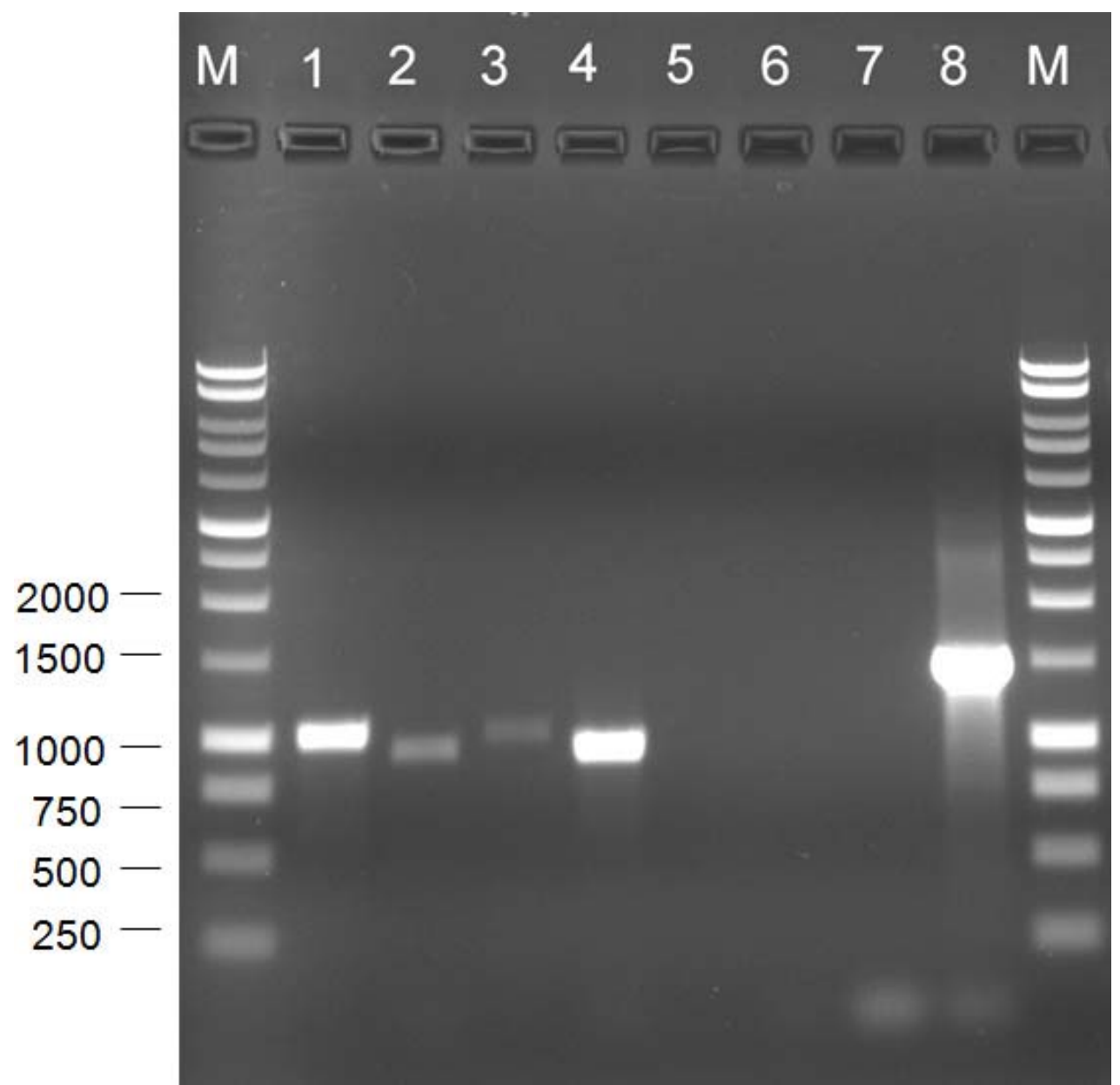

Fig. 2. PCR detection of TSV from CDNAs synthesized from immunocaptured virions (Lanes 1,2 ) and dsRNA template (Lanes 3,4) with MP-specific primers (Lanes 1, 3) and CP-specific primers (Lanes 2, 4). Water controls with MP primers (Lane 5), CP primers (Lane 6), and Hosta virus $X$ (HVX) triple gene block primers (TGB) (Lane 7). HVX TGB clone used as a positive PCR control with HVX TGB primers (Lane 8). M = $1 \mathrm{~Kb}$ DNA ladder (250, 500, 750, 1000, 1500, and 2000 bp markers indicated).

Electrophoresis was done in $0.8 \%$ agarose at 100 volts for 90 min in 1 X TAE buffer. Gel was stained with ethidium bromide. MP and CP amplicons are $1040 \mathrm{bp}$ and $950 \mathrm{bp}$, respectively. 
These results represent the first confirmed report of TSV infecting Hosta spp. in Ohio, and to our knowledge the US, and expand the known natural host range of this virus. Growers nationwide should benefit from the identification of this new Hosta pathogen by gaining awareness of a new viral threat to the industry.

\section{Literature Cited}

1. Fisher, J. R. 2012. First report of Tobacco rattle virus associated with ring spot and line pattern disease of peony in Ohio. Online. Plant Health Progress doi:10.1094/PHP-2012-0711-01-BR.

2. Fisher, J. R. 2012. Identification of three distinct classes of satellite RNAs associated with two Cucumber mosaic virus serotypes from the ornamental groundcover Vinca minor. Online. Plant Health Progress doi:10.1094/PHP-2012-0412-01-RS.

3. Fulton, R. W. 1985. Tobacco streak virus. CMI/AAB Descriptions of Plant Viruses No. 307. Association of Applied Biologists, Wellsbourne, Warwick, UK.

4. King, A. M. Q., Adams, M. J., Carstens, E. B., and Lefkowitz, E. J. 2012. Virus Taxonomy, Ninth Report of the International Committee on Taxonomy of Viruses. Bromoviridae. Pages 965-976. Elsevier Academic Press, Waltham, MA.

5. Sdoodee, R., and Teakle, D. S. 1987. Transmission of tobacco streak virus by Thrips tabaci: a new method of plant virus transmission. Plant Pathol. 36:377-380. doi:10.1111/j.1365-3059.1987.tbo2247.x

6. Valverde, R. A., Nameth, S. T., and Jordan, R. L. 1990. Analysis of double-stranded RNA for plant virus diagnosis. Plant Dis. 74:255-258.

7. Walek, K. P. 2012. International registrar for plant genus Hosta, The Hosta Registry of the American Hosta Society. 